\title{
Yetişkinlerin Çevreye İlişkin Sergiledikleri Davranışlar Gözlem Ölçeği Geçerlilik ve Güvenirlik Çalışması
}

\author{
DOI: 10.26466/opus.557881
}

\author{
Erol Ata* - Mustafa Yildiz ${ }^{* *}$ \\ * Dr., Amasya Üniversitesi, Eğitim Fakültesi, Eğitim Bilimleri Bölümü, Amasya, Türkiye \\ E-Posta: erolata.ea@gmail.com ORCID: 0000-0002-0051-9828 \\ ** Dr., Amasya Üniversitesi, Eğitim Fakültesi, Eğitim Bilimleri Bölümü, Amasya, Türkiye

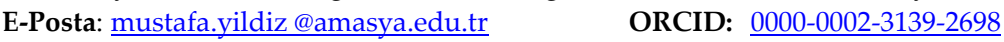

\section{Öz}

Çevre sorunlarının giderek artması, çevresel sorunların belirlenmesini, araştırılmasını ve bireylerde çevre bilinci ve çevreye yönelik olumlu tutum ve davranışların geliştirilmesini daha önemli hale getirmektedir. Bireylerde sürdürülebilir bir çevre bilinci oluşturmada geleneksel öğretim yöntemleri kullanmanın etkisinin ya çok az ya da etkisiz sonuçlar verdiği gözlenmektedir. Bu bağlamda özellikle çocuklarda çevre bilinci geliştirmede, olumlu tutum ve davranışlar oluşturmada yeni öğrenme yöntemlerinin ve gözleyerek (Sosyal) öğrenmenin önemi dikkat çekmektedir. Sosyal öğrenme, özellikle çocuklarm çevredekilerinin hareketlerini, tutum ve davranışların gözlemeye dayanmaktadır. Bu araştırmanın amacı sosyal öğrenmenin önemini dikkate alarak çocuklarm yetişkinlerin çevreye ilişkin sergiledikleri davranışları nasıl algıladıklarına yönelik bir ölçek geliştirmektir. Bu amaca uygun olarak yerli ve yabancı yazın taraması yapılarak 20 maddelik "Yetişkinlerin Çevreye İlişkin Sergiledikleri Davranışlar Gözlem Ölçeği" geliştirilmiştir. Çalışma Amasya ilinde 275 ilkokul ve ortaokul öğrencisiyle yapılmıştır. Yapılan Faktör Analizi sonucu tek boyutlu bir ölçek olarak belirlenmiştir. Ölçeğin Cronbach Alpha güvenirlik katsayısı ise 0.80 olarak tespit edilmiştir. Sonuç olarak ölçeğin öğrencilerin, yetişkinlerin çevreye ilişkin davranışlarını nasıl algıladıklarını ölçmede uygun bir ölçek olduğuna karar verilmiştir.

Anahtar Kelimeler: Çevre bilinci, Çevre eğitimi, Gözleyerek öğrenme 


\title{
Validity and Reliability Study of Observing Adults'- Displayed-Behavior Related to Environment Scale
}

\begin{abstract}
As the environmental issues grow, it has become necessary to search, and determine environmental issues, and develop an awareness that could possibly address such issues. Using traditional learning methods has no or very little impact on developing a sustainable environmental awareness. Therefore, in order to develop environmental awareness in children, it becomes essential to use new learning approaches such as social learning theory instead of the traditional ones. Observational learning is a learning method in which children learn by observing the objects around themselves. Using the social learning, the purpose of this study is to develop an instrument that can measure how children perceive the kinds of behaviors that adults display related to environmental issues. In order to achive the goal, local and foreign literature were reviewed, and an instrument, lenght of 20 items, was developed, called "Observing adults'-displayed-behavior related to environment scale". The study sample was consisted of 275 primary and middle students located in Amasya, Turkey. The data was analyzed using exploratory factor analysis, and the findings suggested that the instrument was unidimensional. The reliability coefficient of the scale (Chronbach Alpha) was calculted as 0.80. Thus, it can be concluded that the developed instrument has validity and reliability evidence justifying the use of the instrument.
\end{abstract}

Keywords: Environmental awareness, Environment educations, Observational learning 


\section{Giriş}

Yaşadığımız çevreye ilişkin problemler yalnızca teknoloji ve kanunlarla çözülecek türden problemler değildir. Bu çözüm yolları ancak kişisel davranış değişiklikleriyle gerçekleştirilebilir. Davranışların değiştirilmesi de bireylerin tutumlarını, bilgi ve değer yargılarını değiştirmekle mümkün olabilir (Korfiatis, Hovardas, ve Pantis, 2004). Öğrencileri gelecekteki hayatlarına hazırlamak, aktif sınıf yaşantılarını ve başarıyla sonuçlanmış öğrenmeleri gerektirir. Öğrenciler hayatlarının yaklaşık üçte birini okullarda geçirirler. Bu süreç içerisinde öğrendikleri de büyük ölçüde değişmez ve kalıcı olarak kişiliklerini oluşturur. Öğrencilerin sosyalleşmesi büyük ölçüde onların kişisel yetenek ve yeterliklerine bağlıdır. Bu yetenek ve yeterlikler de etkili, karşılıklı anlayış, işbirlikçi öğrenme ve deneyimlenen okul yaşantılardan oluşur. Başarılı öğrenmeler öğrenci ve öğretmenler tarafından kullanılan yöntemlerle yakından ilgilidir (Kostowa ve Atasoy, 2008).

Öğrenme, bilgi, beceri, strateji, inanç, tutum ve davranışları kazanmayı ve değiştirmeyi içerir. İnsanlar bilgiyi, bir dili öğrenmeyi, motor ve sosyal becerileri öğrenirler ve bunlar değişik şekillerle olabilir (Shunk, 2012). Araştırmacılar öğrenmenin önemi konusunda hem fikirdirler fakat öğrenme süreçleri, sonuçları ve nedenleri konusunda farklı düşünceye sahiptirler. Öğrenmenin üç önemli kriteri tanımlanmaktadır:

1. Öğrenme değişimi içerir.

2. Öğrenme süreçtir, zaman içerisinde devam eder.

3. Öğrenme deneyim yoluyla devam eder.

Öğrenmenin nasıl gerçekleştiğini açıklayan çok sayıda öğrenme teorisi vardır. Bunlardan en dikkati çekenleri; Davranışçı yaklaşımlar (Klasik şartlanma, operant şartlanma vb.), Sosyal Bilişsel teori (Model olma, öz yeterlik vb.), Bilişsel öğrenme süreçleri yaklaşımları ve Deneysel öğrenme (Dewey) yaklaşımlarıdır (Shunk, 2012; Zhou ve Brown, 2014). En iyi bilinen gelişimsel teoriler, çocuk gelişiminde onun sosyal ilişkilerine ve özerklik gelişimlerine odaklanmaktadır. Bu süreç içerisinde çocukların doğaya bağlılıkları beslenir ise çocuklar doğal çevreye ilişkin edinmeye devam ederler ve çevreleri ile ilişkiyi daha iyi anlayabilirler. Bunun için çevresel eğitim çalışmalarına ilk çocukluk döneminden itibaren başlanmalıdır. İlk yaşlardan itibaren çocukların çevresel deneyimlerinin artması, 
çevreye karşı farkındalığın oluşmasını daha çok kolaylaştıracaktır (Lillian, 2003, s.3; Wilson, 2009). İleri yaşlarda yetişkinliğe kadar aileler ve eğitimciler rol model olarak çocukların olumlu çevresel değer ve davranışlar geliştirmelerine yardım ederler. Eğer bu destek olmazsa çevreye zarar verici ve ihmal edici davranışlar ortaya çıkabilir (Green, 2015). Bireylerde sadece zihinsel düzeyde bilgi hazinesi oluşturmak, davranış ve alışkanlıkları çevreye duyarlı hale getirmemektedir. Bilgilerin içselleştirilmesi ve çevre bilinci oluşturulması asıl istenilen sonuçlar olmalıdır (Öztürk, 2013). Çevre eğitimi, bireylerin, sosyal grupların insan, medeniyet ve doğal çevre arasındaki ilişkiyi anlamak ve takdir etmek için gerekli olan temel becerileri geliştirmek için değerlerin belirlenmesi ve fikirlerin açıklığa kavuşturulması süreci olarak değerlendirilmektedir. Çevre eğitimi, çevresel sorunların çözümünde doğrudan yer almasa da yine de sürdürülebilir gelişme aracı olarak, yeni tutumlar, davranışlar, değerler bilgi ve beceriler geliştirerek öğrencilerde, vatandaşlarda ve sosyal gruplarda çevresel ahlaki davranışlar oluşturmayı amaçlamaktadır (Zachariou, Tsami, Chalkias ve Bersimis, 2017; Knapp, Volk, Hungerford ve Bluhm, 1990). Çocuklarda çevre bilincinin gelişimi için, doğaya sevgiyle yaklaşmalarını ve doğayı tanımalarını sağlayacak ve doğrudan doğru davranışların yapıldığı rol model olunan, bitkilere ve hayvanlara nazik davranılan, malzemelerin geri dönüşümlerinin kullanıldığı ve yaban hayatı için açık yaşam alanlarının kurulduğu ve sürdürüldüğü model davranış yaklaşımların etkili olduğu ifade edilmektedir (Korfiatis, Hovardas ve Pantis, 2004; Soydan, 2015; Wilson, 1996). Çevre eğitimine ilişkin yapılan çalışma ve araştırma sonuçlarına göre okullarda uygulamaya konulan derslerin etkililiğinin ve çevre duyarlılı̆̆ 1 geliştirmek amacıyla yapılan etkinlik ağırlıklı çalışmaların genelde istenilen sonuçları vermediği,ve çabaların çoğunun boşa gittiğini göstermektedir (Sağır, Aslan ve Cansaran, 2008; Şimşekli, 2004: Uzun ve Sağlam, 2005; Ünal ve Dımışık, 1999; Yücel ve Morgil, 1999; Zachariou, Tsami, Chalkias ve Bersimis, 2017).

Bütün bu ele alınan sonuçlar göstermektedir ki çevre eğitimi çalışmalarını yeni bir bakış açısıyla değerlendirmek ve Sosyal Bilişsel (Model alma yoluyla) Öğrenme Modeli üzerinde odaklanmayı akla getirmiştir. Öğrenciler çevreye ilişkin davranışları öğrenirken şüphesiz olarak yakın çevreden etkilenmektedirler. Öğrenciler genel olarak yetişkinlerin çev- 
reye ilişkin davranışlarını nasıl algılamaktadır? Bu çerçevede Sosyal Öğrenme Kuramı (SÖK) ya da diğer adıyla gözleyerek öğrenme kuramı Bandura'nın geliştirdiği başkalarının davranışlarını gözlemeye ve model almaya dayalı bir öğrenme yöntemi dikkate alınarak çevre eğitimine katkısı ele alınmıştır. Sosyal öğrenme teorisinde bir modelin davranışı gözlendiktikten sonra gözleyenin davranışı olumlu ya da olumsuz yönde değişmektedir (Bandura, 1977; Bandura, 1986).

Gözlemle öğrenmeni temel öncülü, insanların gözlem yoluyla öğrenmeleri olmuştur. Bu süreç ayrıca, öğrenme ve modelleme olarak tanımlanır. Gözleyerek öğrenme, modellerin ulaşılabilirliğine bağlıdır. Bir öğretmenin ya da sınıf arkadaşının davranış ya da becerileri model kavramı içerisinde açıklanır. Sözlü ya da yazılı ifadeler, görsel ya da sözel ses kayıtları ya da bireylerin performanslarının diğer halleri modelleme biçimi olarak gösterilir. Çocukların bir davranışı öğrenebilmeleri için o davranışın başkaları tarafında nasıl yapıldığını görmeleri gerekmektedir. Model olan kişi gözlenerek yeni bilişsel beceri ve davranışlar öğrenilebilir. Çocuklar, modelin yapmış olduğu davranışlar ve sonuçlarını gözlemleyerek neyin nasıl yapılabileceğini ve neyin nasıl yapılmaması gerektiğini, modelin gözlemlenerek motivasyon sağlamayı, çevrenin ve nesnelerin nasıl kullanılacağını öğrenirler. Ayrıca modellerin yüksek statülü olmaları, okullarda öğretmenlerin ve toplumda liderlerin örnek davranışlar göstermeleri, modelle gözlemleyen arasında etkileşimi artırır. Çevresel faktörler bireylerin kararını etkilerken çevrede olan olaylar; bireye nasıl davranması gerektiği konusunda yol gösterici olabilmektedir SÖK'e göre yeni davranışların ya da becerilerin gözlem yoluyla öğrenilmesi birbiriyle bağlı dört süreci içerir:

1. Dikkat: Davranışa yönelme.

2. Tutma: Modelin davranışlarının saklanması.

3. Motivasyon: Davranışı örnek almak, aynısını yapmak için iyi bir nedene sahip olma.

4. 4-Üretim: Davranışın örnek alınması (Bandura, 1978; Shunk, 2012; Korkmaz, 2011; Zhou ve Brown, 2014).

Açıkça görülmektedir ki Sosyal Öğrenme Modelinde çevreye ilişkin öğrenmelerin önemi büyüktür. Bunun önemi dikkate alınarak acaba çocuklar yetişkinlerin çevreye ilişkin sergiledikleri davranışları nasıl göz- 
lemliyorlar ve algilıyorlar? Bu sorunu cevabını bulmak amacıyla "Yetişkinlerin Çevreye İlişkin Sergiledikleri Davranışlar Ölçeği" geliştirilmek istenmiştir

\section{Yöntem}

Araştırma yetişkinlerin çevreye ilişkin sergiledikleri davranışların öğrenciler tarafından nasıl algılandığını ölçmek amacıyla yapılan betimsel bir ölçek geliştirme çalışmadır.

\section{Araştırma Grubu}

$\mathrm{Bu}$ araştırmanın evrenini Amasya ilindeki ilkokul ve ortaokul öğrencileri oluşturmaktadır. Araştırmanın örneklemini (çalışma grubu) ise bu okullardan rastgele seçilmiş 275 öğrenci oluşturmaktadır. Örneklem büyüklüğü olarak homojen gruplarda evrenin 50.000 kişi ve örneklemin 245 kişi yeterli olacağ $(C a n, 2014)$ belirtilmiştir. Bu araştırmada 275 öğrenciye ulaşılmıştır sayısı alınmıştır. Amasya genelindeki ilkokul ve ortaokul öğrencilerine ilişkin sayılar Tablo 1 de verilmiştir (Amasya MEM, 2015).

Tablo 1. Amasya Geneli İlkokul ve Ortaokul Öğrenci Sayıları

\begin{tabular}{llc}
\hline Okul Türü & Öğrenci Sayısı & Alınan Örneklem \\
\hline Illkokul & 17.700 & 145 \\
Ortaokul & 18.277 & 130 \\
\hline Toplam & 35.977 & 275 \\
\hline
\end{tabular}

Araştırmaya katılanlara ait demografik özellikler aşağıda Tablo 1'de verilmiştir. Tablo 1'e göre Araştırmaya katılanların öğrencilerin \%53,1'i kız, \%56,9'u erkektir. Öğrencilerin \%29,5'i ilkokul 3'üncü sinıf, \%23,3'ü ve 4'üncü sınıf, \%48,2' si ortaokul öğrencisinden oluşmaktadır. Araştırma grubundaki öğrencilerin annelerinin \%26,5'i ilkokul ve ortaokul düzeyinde $\% 36^{\prime}$ l lise düzeyinde ve $\% 37,5^{\prime} u$ üniversite ve yüksek lisans düzeyinde öğrenime sahiptirler. Ayrıca öğrencilerin babalarının \%16'1 ilkokul ve ortaokul düzeyinde, $\% 35,6^{\prime}$ sı lise düzeyinde ve $\% 48,4^{\prime}$ ü üniversite ve yüksek lisans düzeyinde öğrenime sahiptirler. 
Tablo 2. Araştırmaya Katılanlara Ait Demografik Özellikler

\begin{tabular}{llc}
\hline Özellik & f & \% \\
\hline Cinsiyet & 129 & 53,1 \\
Kız & 146 & 56,9 \\
Erkek & & \\
Sinıf Düzeyleri & 81 & 29,5 \\
3 & 64 & 23,3 \\
4 & 31 & 11,3 \\
5 & 35 & 12,7 \\
6 & 29 & 10,5 \\
7 & 35 & 12,7 \\
8 & & \\
Anne Öğrenim Düzeyi & 41 & 14,9 \\
İlkokul & 32 & 11,6 \\
Ortaokul & 99 & 36,0 \\
Lise & 85 & 30,9 \\
Üniversite & 18 & 6,5 \\
Yüksek lisans & & \\
Baba Öğrenim Düzeyi & 15 & 5,5 \\
İkokul & 29 & 10,5 \\
Ortaokul & 98 & 35,6 \\
Lise & 118 & 42,9 \\
Üniversite & 15 & 5,5 \\
Yüksek lisans & & \\
\hline
\end{tabular}

\section{Bulgular}

Bu çalışmanın amacı Yetişkinlerin Çevreye İlişkin Sergiledikleri Davranışlar Gözlem Ölçeği (YÇISDGÖ) oluşturan maddeler arasındaki korelasyonu açıklayan faktör yapısının ortaya konmasıdır. Verilerin analizinde $\mathrm{R}$ yazılıminda (R Core Team, 2018) yer alan QuantPsyc (Fletcher, 2012) ve psych (Revelle, 2018) paketleri ile Mplus (Muthén \& Muthén, 2019) kullanilmıştır.

İlk olarak, eldeki veri kayıp veri bakımından gözden geçirilmiştir. 8 adet gözlemin kayıp olduğu tespit edilmiştir. Kayıp veriler bütün verinin $\% 0.01$ 'i kadarıdır. Kayıp verinin miktarı kayıp veri analizi yürütülmesine imkan tanımayacak kadar azdır dolayısıyla kayıplık, türü itibarı ile MCAR'dır (Tamamen tesadüfi kayıp=missing completely at random; Enders, 2010).

Kayıp veriler ait oldukları bireyin ortanca değeri ile değiştirilmiş ve bu şekilde örneklem büyüklügünün korunması amaçlanmıştır. Değişkenler 
kayıp veri bakımından incelendikten sonra, kategori sıklıkları bakımından gözden geçirilmişlerdir. Her bir değişken için, frekans yüzdeleri ortalama \%33, en az yaklaşık \%10, ve en çok yaklaşık \%57 olarak gerçekleşmiştir. Değişkenlerin frekanslarının incelenmeleri neticesinde, değişkenlerde dikkat çekici bir durum gözlenmemiştir. Ayrıca, açımlayıcı faktör analizi için en yüksek olabilirlik (maximum likelihood-ML) kestirim metodunun kullanımı ilk olarak düşünülmüş fakat bu metodun temel sayıltısı olan çok değişkenli normallik testi neticesinde ölçekte bulunan maddelerin çok değişkenli normal bir dağılıma gösteremediği tespit edilmiştir. Çok değişkenli normallik testinin bulguları Tablo 3'te yer almaktadır.

Tablo 3. Çok değişkenli normallik testi sonuçları

\begin{tabular}{llll}
\hline & Beta hat & Kappa & p \\
\hline Mardia eğiklik & 39.95 & 1831.35 & $<0.05$ \\
Mardia basıllık & 446.28 & 1.75 & 0.07 \\
\hline
\end{tabular}

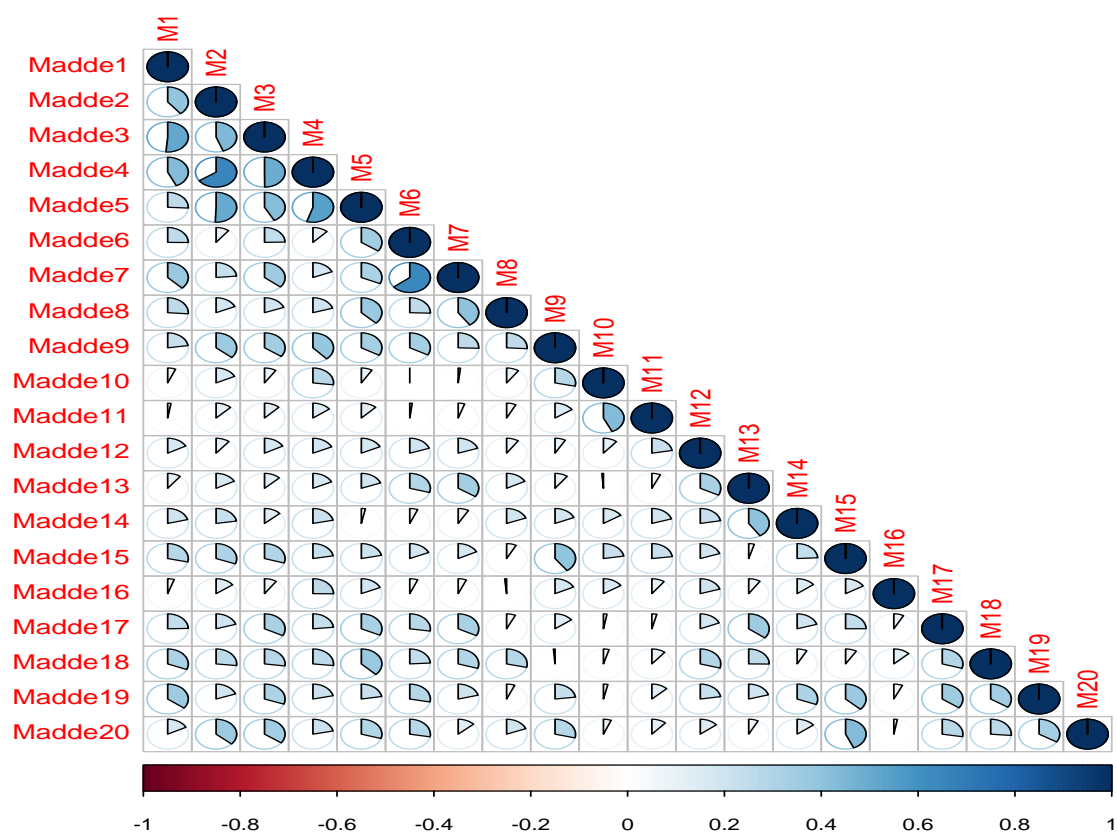

Grafik 1. Maddeler arası polikorik korelasyonlar

Holgado-Tello, Chacón-Moscoso, Barbero-García, Vila-Abad (2010) açımlayıcı faktör analizi çalışmalarında, eğer Likert tipi veri kullanılmışsa, 
pearson momentler çarpımı korelasyon yerine polikorik korelasyon kullanımının önemine dikkat çekmiştir. YÇíSDG ölçeği ile toplanmış olan veriler Likert tipi bir ölçek olmaları sebebiyle değişkenler arası ilişkiler polikorik (polychoric) korelasyonlar ile hesaplanmıştır. 20 maddeli YÇİSDG ölçeğinin polikorik korelasyonlar tablosu Grafik 1' de görüldüğü gibi görsel hale getirilmiştir.

Faktör sayısının belirlenmesinde ve faktör çıkarımı süreçlerinde polikorik korelasyon matrisinin köşegen değerleri olarak karesi alınmış çoklu korelasyonlar (squared multiple correlations) esas alınmıştır. Bu sayede faktör çıkarımı özerk varyansın diğer maddeler tarafından paylaşılan kısmı üzerinden gerçekleşmiş olacaktır. İlk olarak faktör sayısı belirlenmeye çalışılmıştır. Bu maksatla istatistiksel metotlar ve kuramsal gereklilikler birlikte harmanlanmıştır. Faktör sayısını belirlemede kullanılan metotlardan biri öz değeri 1'den büyük olan her öz değeri bir faktör olarak düşünmektir (Kaiser, 1960). Son yıllarda faktör sayısının belirlenmesinde başvurulan bir metot olarak paralel analiz (Horn, 1965) ayrıca ön plana çıkmaktadır ve bu çalışma için kuramsal gerekliliklerin yanı sıra her iki metottan da yararlanılmıştır.

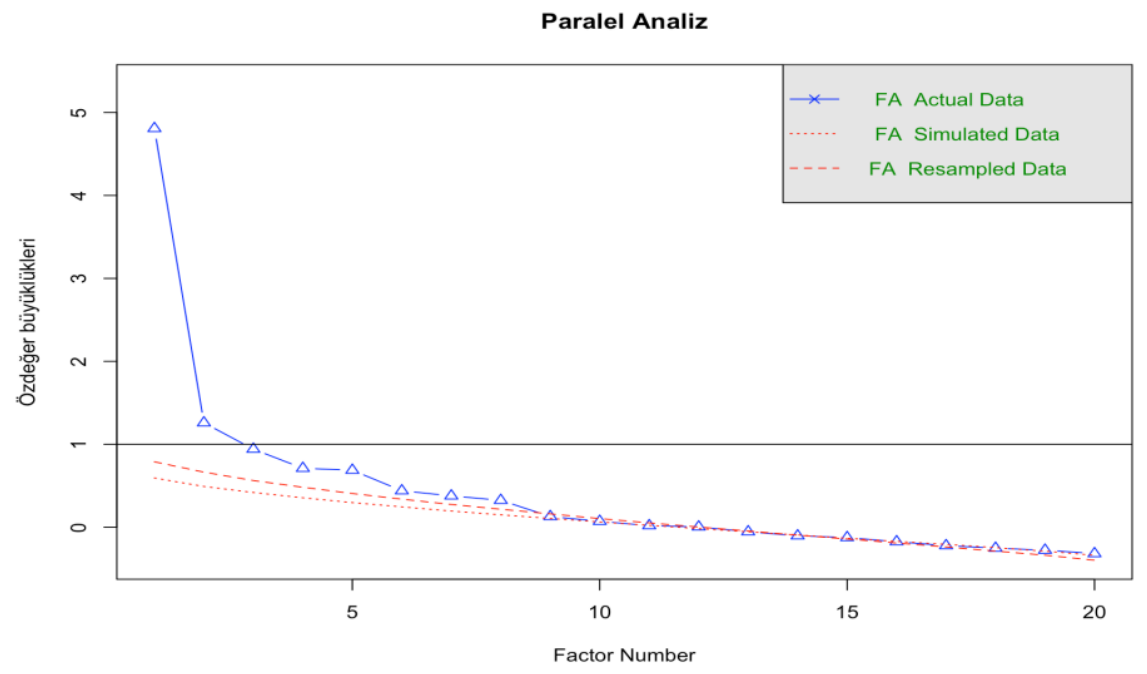

Grafik 2. Öz değerler ve paralel analiz 
Grafik 2 incelendiğinde öz değer büyüklüklerinden hareketle maddeler arası korelasyonu açıklayabilecek faktör sayısının 1 ya da 2 olabileceği görülmektedir. Paralel analiz sonuçlarına göre ise faktör sayısının 1 ile 8 arasında değişmekte olabileceği görülmektedir. Dolayısı ile 1 faktörü içeren çözümden 8 faktörü içeren çözüme kadar olan olası senaryolar kuramsal ve istatistiksel açıdan incelenmiştir.

Sadece öz değerlere ve paralel analiz grafiğine bakarak faktör sayısının belirlenmesi oldukça güç olduğu için 1 faktörlü yapıdan 8 faktörlü yapıya kadar tüm olası senaryolar kuramsal arka planda göz önünde bulundurularak Mplus 6.0 (Muthén \& Muthén, 2012) yazılımı üzerinde gözden geçirilmiştir. Çok değişkenli normallik sayıltısı gerçekleşmediği için kestirim yöntemi olarak WLSMV (weighted least squares means and variances) tercih edilmiş olup, faktör sayısı 1'den fazla olan çözümler için döndürme metodu olarak binişik döndürme metotlarından GEOMIN kullanılmıştır. Faktör sayısının 1 ile 8 arasında oluşabilecek her değeri için ki-kare verimodel uyumu testine ek olarak, RMSEA (root mean square error of approximation), CFI (comparative fit index), TLI (Tucker-Lewis index) ve SRMR (standardized root mean resiadual) değerleri kontrol edilmiştir. Tablo $4^{\prime}$ te yer alan uyum indeksleri incelendiğinde faktör sayısının 4 ve üzeri olduğu durumlarda faktörlerde oluşan belirsizlik arttığı için ki-kare testi anlamlı bir sonuç vermemiştir. Faktör sayısının 1'den 3'e artması ile birlikte parametre kullanımının artmasına bağlı olarak model-veri uyumunda iyileşme gözlenmiştir. Sonuç olarak 1, 2 ve 3 faktörlü yapıların daha detaylı bir incelemeye tabi tutulmasına karar verilmiştir.

Tablo 4. Faktör sayısına göre modellerin veriye uyum düzeyleri

\begin{tabular}{|c|c|c|c|c|c|c|c|c|c|}
\hline Çözüm & $\begin{array}{l}\text { Ki- } \\
\text { kare }\end{array}$ & $\mathrm{sd}^{*}$ & $\mathrm{p}^{*}$ & RMSEA & Alt $^{*}$ & Üst* & CFI & TLI & SRMR \\
\hline 1.Faktör & 532,9 & 170 & $<0,05$ & 0,08 & 0,07 & 0,09 & 0.74 & 0,71 & 0,10 \\
\hline 2.Faktör & 296,9 & 151 & $<0,05$ & 0,05 & 0,04 & 0,06 & 0.89 & 0,87 & 0,07 \\
\hline 3.Faktör & 196,9 & 133 & $<0,05$ & 0,04 & 0,03 & 0,05 & 0.95 & 0,93 & 0,05 \\
\hline 4.Faktör & 133,4 & 116 & 0,12 & 0,02 & 0,00 & 0,03 & 0.98 & 0,98 & 0,04 \\
\hline 5.Faktör & 96,1 & 100 & 0,58 & 0,00 & 0,00 & 0,02 & 1 & 1 & 0,03 \\
\hline 6.Faktör & 67,7 & 85 & 0,91 & 0,00 & 0,00 & 0,01 & 1 & 1 & 0,02 \\
\hline 7.Faktör & 50,6 & 71 & 0,96 & 0,00 & - & - & 1 & 1 & 0,02 \\
\hline 8.Faktör & 37,0 & 58 & 0,98 & 0,00 & - & - & 1 & 1 & 0,01 \\
\hline
\end{tabular}


Tablo 5. Standartlaştırılmış faktör yükleri

\begin{tabular}{|c|c|c|c|}
\hline Madde & $\begin{array}{l}\text { Faktör } \\
\text { yükleri } \\
\left(\lambda_{i}\right)\end{array}$ & $\begin{array}{l}\text { Ortak } \\
\text { varyans } \\
\left(\mathrm{h}^{2}\right)\end{array}$ & $\begin{array}{l}\text { Özerk } \\
\text { varyans } \\
\left(\mathrm{u}^{2}\right) \\
\end{array}$ \\
\hline $\begin{array}{l}\text { 1-Yetişkinlerin çevre sorunlarına } \\
\text { duyarlı olduklarını gözlüyorum. }\end{array}$ & 0,56 & 0,34 & 0,69 \\
\hline $\begin{array}{l}\text { 2-Yetişkinlerin plastik atıkları geri dönüşüm } \\
\text { kutusuna attıklarını gözlüyorum. }\end{array}$ & 0,58 & 0,22 & 0,66 \\
\hline $\begin{array}{l}\text { 3-Yetişkinlerin çevre dostu ürünler seçmeye özen } \\
\text { gösterdiklerini gözlüyorum. }\end{array}$ & 0,47 & 0,36 & 0,78 \\
\hline $\begin{array}{l}\text { 4-Yetişkinlerin cam şişeleri geri dönüşüm } \\
\text { kutusuna attıklarını gözlüyorum. }\end{array}$ & 0,60 & 0,38 & 0,64 \\
\hline $\begin{array}{l}\text { 5-Yetişkinlerin atık kağıtları geri } \\
\text { dönüşüm kutusuna attıklarını gözlüyorum. }\end{array}$ & 0,62 & 0,19 & 0,62 \\
\hline $\begin{array}{l}\text { 6-Yetişkinlerin gereksiz ışıkları } \\
\text { kapattıklarını gözlüyorum. }\end{array}$ & $0 ., 44$ & 0,31 & 0,81 \\
\hline 7-Yetişkinlerin su tasarrufu yaptıklarını gözlüyorum & 0,56 & 0,18 & 0,69 \\
\hline $\begin{array}{l}\text { 8-Yetişkinlerin yerde gördükleri çöpü çöp } \\
\text { kovasına attıklarını gözlüyorum. }\end{array}$ & 0.42 & 0,22 & 0,82 \\
\hline $\begin{array}{l}\text { 9-Yetişkinlerin kullanılmış pilleri geri dönüşüm } \\
\text { kutusuna attıklarını gözlüyorum. }\end{array}$ & 0,47 & 0,04 & 0,78 \\
\hline $\begin{array}{l}\text { 10-Yetişkinlerin çevreyle ilgili kampanyalara } \\
\text { katıldıklarını gözlüyorum. }\end{array}$ & 0,20 & 0,08 & 0,96 \\
\hline $\begin{array}{l}\text { 11-Yetişkinlerin çevre ve doğa yürüyüşlerine } \\
\text { katıldıklarını gözlüyorum. }\end{array}$ & 0,28 & 0,12 & 0,92 \\
\hline $\begin{array}{l}\text { 12-Yetişkinlerin çevre ve doğayla ilgili belgesel } \\
\text { programları izlediklerini gözlüyorum. }\end{array}$ & 0.34 & 0,32 & 0,88 \\
\hline $\begin{array}{l}\text { 13-Yetişkinlerin hayvanlara iyi } \\
\text { davrandıklarını gözlüyorum. }\end{array}$ & 0,57 & 0,12 & 0,68 \\
\hline $\begin{array}{l}\text { 14-Yetişkinlerin sahipsiz hayvanları } \\
\text { beslediklerini gözlüyorum. }\end{array}$ & 0,34 & 0,15 & 0,88 \\
\hline $\begin{array}{l}\text { 15-Yetişkinlerin sigara izmaritlerini yere } \\
\text { atmadıklarını gözlüyorum. }\end{array}$ & 0,39 & 0,07 & 0,85 \\
\hline $\begin{array}{l}\text { 16-Yetişkinlerin özel araçları yerine toplu taşıma } \\
\text { araçları kullandıklarını gözlüyorum. }\end{array}$ & 0,26 & 0,32 & 0,93 \\
\hline $\begin{array}{l}\text { 17-Piknik yerlerinden ayrılırken çevre } \\
\text { temizliği yaptıklarını gözlüyorum. }\end{array}$ & 0,57 & 0,14 & 0,68 \\
\hline $\begin{array}{l}\text { 18-Az elektrik harcayan araçları tercih } \\
\text { ettiklerini gözlüyorum. }\end{array}$ & 0.37 & 0,16 & 0,86 \\
\hline $\begin{array}{l}\text { 19-Yetişkinlerin kapalı yerlerde sigara } \\
\text { içmediklerini gözlüyorum. }\end{array}$ & 0,40 & 0,23 & 0,84 \\
\hline 20-Yetişkinlerin yerlere tükürmediklerini gözlüyorum. & 0,48 & 0,23 & 0,77 \\
\hline
\end{tabular}


Yapılan incelemeler neticesinde 2 ve 3 faktörlü yapı, her ne kadar uyum indeksleri açısından daha iyi durumda gözükseler de faktör yüklerinin ima ettiği kuramsal yapı bakımdan anlamlı bulunamamışlardır. Ayrıca 3 faktörlü yapıda faktörler arası korelasyon büyüklüklerinden iki tanesinin 0 ya da sıfıra yakın oluşu bu bulguyu destekler niteliktedir. Her ne kadar tek faktörlü yapı uyum indeksi (RMSEA) açısından 'kabul edilebilir' düzeydeyse de (MacCallum, Browne ve Sugawara, 1996), elde edilen puanların anlamlandırılabilirliği bakımından faktör sayısının daha fazla olduğu durumlara göre daha olumlu özelliklere sahip olduğu düşünülmüştür. Dolayısı ile YÇİSDG ölçeğinin tek faktörlü bir yapıda ele alınması uygun görülmüştür. Faktör sayısı belirlendikten sonra, madde-faktör yüklenmeleri, ortak varyans (common variance) ve özerk varyans (unique variance) değerleri hesaplanmış ve Tablo 5'te verilmiştir. Bu tabloda bazı maddelerin (Madde 10, Madde 11 ve Madde 16) yüklenmeleri bakımından düşük değerlere sahip oldukları görülmektedir. Bu maddelerin ölçekten çıkarılması alan uzmanı (ilk yazar) tarafından değerlendirilmiş ve kapsam geçerliliğine ait gereklilikler göz önünde bulundurularak maddelerin atılmaması yönünde bir karara varılmıştır. Son olarak, ölçeğin iç tutarlılığını belirlemek için alfa katsayısı (Cronbach, 1951) kullanılmış ve güvenilirlik 0.80 olarak hesaplanmıştır

\section{Sonuç}

Bu çalışma sonucunda Yetişkinlerin Çevreye İlişkin Sergiledikleri Davranışlar Gözlem Ölçeği (YÇiSDGÖ)' den elde edilen verilere bakıldığında ölçeğin madde yük değerlerinin genelde yüksek olduğu görülmektedir (Madde 10-11 ve 16 hariç). Ölçeğin güvenirlik katsayısı 0.80'dir. Bu durumda güvenirlik sonuçlarının oldukça yüksek değerlerde olması güvenilir olduğunu göstermektedir (Can, 2017). Madde sayısının az olmasının kullanım açısından kolaylıklar sağlayacağı düşünülmektedir. Ölçek ilköğretim (İlk ve ortaokul) öğrencileri üzerinde çalışarak geliştirilmiştir. Ayrıca diğer eğitim kademelerindeki öğrenciler ve yetişkinler için de yetişkinlerin çevreye ilişkin sergiledikleri davranışlara ilişkin gözlem ölçekleri geliştirilebilir. Sonuç olarak geliştirilen bu ölçeğin alanda yapılacak çalışmalar için uygun bir yapıda olduğuna karar verilmiştir. 


\title{
EXTENDED ABSTRACT
}

\section{Validity and Reliability Study of Observing Adults'- Displayed-Behavior Related to Environment Scale}

\author{
Erol Ata - Mustafa Yıldız \\ Amasya University
}

The problems we encounter in our environment are not those that can be only dealt with technological means or legislations. The solutions for these problems can be found through personal behavior changes, and this can only be possible thanks to changing attitudes, knowledge and values of individuals. Preparing students for their future lives requires them to have active classroom experiences and successful learnings. Students spend a great amount of time in schools. The learnings they have during school time don't differ significantly and form their identities.

Socialization of students highly relies on their personal skills and competences. These consist of school experiences characterized by effective mutual understanding and cooperative learning. Successful school outcomes are closely related to methods used by teachers and students. Learning encompasses knowledge, skill, strategy, belief, attitude and learning new behaviors or changing the available ones. People learn any knowledge, acquire any language, and obtain motor and social skills through different ways.

There have been several learning theories explaining how learning takes place. Among the most notable theories of learning are Behaviorist Approaches (Classical Conditioning, Operant Conditioning, etc.), SocialCognitive Theory (Being a role model, Self-Efficacy, etc.), Cognitive Learning Approaches and Experiental Learning (Dewey). The most accepted theories focus on children's social relations and autonomy developments in the childhood period. If children are enabled to develop commitment to nature during this period, they continue to learn about environment and can figure out the relationship with their environments. Therefore, the environmental education practices should be conducted from the very 
early years of childhood. Having environmental experiences during childhood will enable children to raise awareness on environmental issues easily. Educators and parents help children develop positive attitudes and behaviors towards environment, being a role model for them. Without this support, there may occur damaging and neglectful behaviors for the environment. Making individuals acquire knowledge doesn't make their habits and behaviors sensitive towards the environment. Internalizing and raising environment awareness must be a priority to get expected outcomes. Environmental education is considered as a process that lets individuals or social groups figure out the relationships among human, civilization and natural environment and that allows them to develop basic skills and understand the ideas on the issue. As a sustainable development tool, environmental education aims to make students, citizens and social groups have environmental ethic considerations, developing new attitudes, behaviors, values, knowledge and skills although those don't directly engage in solving the environmental problems.

In order to boost the awareness of children on environmental consciousness, previous research advocates those approaches in which children can develop affection for the nature and know it better, the rigt role models exist, plants and animals are well treated, recycling is a priority, and open habitats for the wildlife have been settled.

The studies on the environmental education have revealed that the efficacy of the practices on environmental consciousness in schools don't yield expected results and the efforts have evolved into useless actions. Previous research indicates that a new perspective is required to address the environmental education. Correspondingly, Social-Cognitive Learning Model (Taking Role Model) is considered as an alternative for an effective environmental education.

Students are affected by their environments while developing attitudes and displaying behaviors on the environment. How do usually students perceive the behaviors of adults? In this sense, this research is to examine the contribution of Social Learning Theory, namely learning by observing and taking role model, to the environmental education. In Social Learning Theory, the behaviors of an observer are affected negatively or positively after observation of the behaviours of others. 
The basic component of learning by observation is to learn by observing others. This process is also called as learning and modelling. Learning by observation is based on the accessibility of the models. Behaviors or skills of a teacher or a classmate are explained in the scope of the model concept. Verbal or written expressions, visual or audio recordings as well as the individual performances are seen as modelling styles. Children need to see a behavior that they are expected to display. By observing the model, they can develop new cognitive skills and behaviors. Children figure out how they should act or shouldn't, by observing the behaviors of the model. They also develop their motivation and learn how to use the environment and objects around them through observation. Furthermore, the high status held by the model and being respected individuals as teachers in the society increase the interaction between the observer and the model. The environmental factors impact the decisions of the individuals, while the events can guide them about their behaviors.

In conclusion, it can be said that the item loads of the scale are mostly at high level (except the items 10,11 and 16) when the data about the Adult Behaviors towards the Environment Scale are examined. The reliability coefficient of the scale is .80 , which means that the scale is a reliable data collection instrument. The scale was developed through the data on primary and secondary school students. In this sense, it can be suggested that similar scales on higher level students can be developed to measure their environmental beheaviors. In a nutshell, this scale has been found a reliable and valid instrument.

\section{Kaynakça / References}

Amasya MEM. (2015). Stratejik plan. 15.05.2019 tarihinde http:/meb.gov.tr/dowland/arge/2015-2019SP.pdf adresinden ulaşılmiştır.

Bandura, A. (1977). Self-efficacy: Toward a uniying theory of behavioral change. Psyhological Reviev, 84(2), 191-215.

Bandura, A. (1978). Social learning theory of agression. Journal of Communication. 28(3), 12-29.

Bandura, A. (1986). Social foundations of thought and action. A social cognitive theory. Englewood Cliffs. NJ. Prentice Hall. 
Bandura, A. (2001). Social cognitive theory: An agentic perspective. Annual Review Psychology, 52,1-26.

Bayrakçı, M. (2007). Sosyal öğrenme kuramı ve eğitimde uygulanması. Sakarya Üniversitesi Ĕ̆itim Fakültesi Dergisi, 14,198-210

Büyüköztürk, Ş. (2009). Sosyal bilimler için veri analizi el kitabı. Ankara: Pegem. Can, A. (2014). SSPS ile nicel veri analizi. Ankara: Pegem.

Çimen, O. (2008). Çevre eğitiminde tatlısu ekosistemleri konusundaki temel kavramların üniversite öğrencileri tarafindan algılanma düzeyleri. Yayınlanmamış yüksek lisans tezi, Gazi Üniversitesi Eğitim Bilimleri Enstitüsü, Ankara.

Cronbach, L. J. (1951). Coefficient alpha and the internal structure of tests. Psychometrika， 16, 297-334. http://dx.doi.org/10.1007/ BF $\underline{02310555 .}$.

Enders, C. K. (2010). Applied missing data analysis. Guilford press.

Holbert, R.L., Kwak, N. ve Shah, D. V. (2010). Environmental concern, patterns of television viewing, and pro-environmental behaviors. Journal of Broadcasting \& Electronic Media, 47(2), 177-196.

Holgado-Tello, F., P., Moscoso, S., Barbero-García, I., ve Vila, E. (2010). Polychoric versus Pearson correlations in exploratory and confirmatory factor analysis of ordinal variables. Quality $\mathcal{E}$ Quantity, 44(1), 153-165.

Horn, J. L. (1965). A rationale and test for the number of factors in factor analysis. Psychometrika, 30(2), 179-185.

Kaiser, H. F. (1960). The application of electronic computers to factor analysis. Educational and psychological measurement, 20(1), 141-151

Knapp, D. H., Volk, T. L., Hungerford, H. R., ve Bluhm, M. (1990). Global change environmental education module. UNESCO-UNAPT International Environmental Education Program. IEEP. 20.05.2019 tarihinde http://unesdoc.unesco.org/images/0011/001113/111308-eo.pdf adresinden ulaşılmıştır

Korfiatis, K. J., Hovardas, T. ve Pantis, J. D. (2004). Determinants of environmental behavior in societies in transition: Evidence from five European countries. Population and Environment, 25(6), 563-584

Korkmaz, İ. (2011). Sosyal öğrenme kuramı. Ĕ̆itim psikolojisi (Ed. B. Yeşilyaprak.) içinde (s.246-269). Ankara: Pegem.

Kostowa, Z. ve Atasoy, E. (2008). Methods of successful learning in environmental education. Egitimde Kuram ve Uygulama, 4(1) 49-78. 
MacCallum, R. C., Browne, M. W. ve Sugawara, H. M. (1996). Power analysis and determination of sample size for covariance structure modeling. Psychological methods, 1(2), 130-141.

Muthén, L. K., ve Muthén, B. O. (2012). Mplus: Statistical analysis with latent variables. (7th ed.). Los Angeles.

Muthén, L. K., ve Muthén, B. O. (2019). Mplus. The comprehensive modelling program for applied researchers: User's guide, 15.04.2019 tarihinde https://www.statmodel.com adresinden ulaşılmıştır

Rafferty, R. ve Laird, S. G. (2013). Children's observations of place-based environmental education. Journal of Sustainability Education, 2(3). 15.04.2018 tarihinde http://www.susted.org/ adresinden ulaşılmıştır.

R Core Team (2018). R: A language and environment for statistical computing. $R$ Foundation for Statistical Computing, Vienna, Austria. 17.05.2018 tarihinde https://www.R-project.org adresinden ulaşılmıştır.

Revelle, W. R (2018) Psych: Procedures for personality and psychological research. Northwestern University, Evanston, Illinois, USA.

Sağır, Ş. U., Aslan, O. ve Cansaran, A. (2008). İlköğretim öğrencilerinin çevre bilgisi ve çevre tutumlarının farklı değişkenler açısından incelenmesi. Elementary Education Online, 7(2), 15.04.2018 tarihinde http://ilkogretim-online.org.tr adresinden ulaşılmıştır.

Said S, M., Yahaya, N. ve Ahmadun, F. (2007). Environmental comprehension and participation of Malaysian secondary school students. Environmental Education Research, 13 (1), 17-31.

Schunk, D. H. (2012). Learning theories. Boston: Pearson

Soydan, S., Samur, A. Ö., Koçyiğit, S. ve Kiremit, H.Ö. (2015). çocuk ve çevre. Ankara: Vize

Stern, M. J., Frensley, B.T., Powell, R. B. ve Ardoin, N. M. (2018). What difference do role models make? Environmental Education Research, 24, (6), 818-830.

Şimşekli, Y. (2004). Çevre bilincinin geliştirilmesine yönelik çevre eğitimi etkinliklerine ilköğretim okullarının duyarlılı̆̆ı. Uludağ Üniversitesi E $\breve{g} i$ tim Fakültesi Dergisi, 17(1), 83-92

Taycı, F. ve Uysal, F. (2009). Çorluda birinci ve ikinci kademe ilköğretim öğrencilerine çevre eğitimi konusunda uygulanan anket çalışması. Fen, sosyal ve çevre eğitiminde son gelişmeler sempozyumu bildiriler kitabı. 1820 Kasim, Giresun. 
Thomas D. Fletcher (2012). QuantPsyc: Quantitative psychology tools. R package version 1.5, 15.04.2018 tarihinde https://CRAN.R-project.org/package $=$ QuantPsyc adresinden ulaşılmıştır.

Uzun, N. ve Sağlam, N. (2007). Ortaöğretimde çevre eğitimi ve öğretmenlerin çevre eğitimi programları hakkındaki görüşleri. Eurasian Journal of Educational Research, 26, 176-187

Ünal, S. ve Dımışkı, E. (1999). Unesco-Unep himayesinde çevre eğitiminin gelişimi ve Türkiye'de ortaöğretim çevre eğitimi. Hacettepe Üniversitesi Ĕ̆itim Fakültesi Dergisi, 16(17), 142 - 154

Yücel, A.S. ve Morgil, F. İ. (1999). Çevre eğitiminin geliştirilmesi. Balıkesir Üniversitesi Fen Bilimleri Enstitüsü. Dergisi, 1(1), 76-89

Yüksel, G. (2014). Bir bilim olarak eğitimin psikolojik temelleri. Eğitim bilimine giriş, (Ed. Ç. Özdemir) içinde (207-231). Ankara: Pegem.

Zachariou, F., Tsami, E., Chalkias, C. ve Bersimis, S. (2017). Teachers' attitudes towards the environment and environmental education: An empirical study. International Journal Of Environmental \& Science Education, 12 (7), 1567-1593

Zhou, M. ve Brown, D. (2014). Educational learning theories. 17.04.2018 tarihinde $\quad$ https://rrscholar.openrepository.com/rrscholar/bitstream/10758/337833/1/EDUC2130+Textbook+Educational+Learning+Theories.pdf adresinden ulaşılmıştır.

\section{Kaynakça Bilgisi / Citation Information}

Ata, E. ve Yıldız, M. (2019). Yetişkinlerin çevreye ilişkin sergiledikleri davranışlar gözlem ölçeği geçerlilik ve güvenirlik çalışması. OPUSUluslararası Toplum Araştırmaları Dergisi, 13(19), 1010-1027. DOI: 10.26466/opus.557881 